\title{
Being Coloured ANd Looking Coloured
}

Keith Allen, University of York

ka519@york.ac.uk

Intuitively, there is an intimate relationship between being coloured and looking coloured. As Strawson memorably remarked, it is natural to assume that 'colours are visibilia or they are nothing' (1979: 109). But what exactly is the nature of this relationship?

A perennially popular view of the relationship between being coloured and looking coloured starts from the common place that the character of our perceptual experience changes as the conditions in which a coloured object is perceived vary: it changes as we view an object under different illuminants; it changes under one and the same illuminant, depending on whether the object is directly or indirectly illuminated; and it varies independent of this, as the background against which the object is perceived varies. Placing a lot of weight on the idea that objects look or appear different as the perceptual conditions vary, proponents of this view argue that we can understand what it is for something to be coloured in terms of what it is for something to look coloured, where looking coloured is tied to some very specific set of perceptual conditions.

In this paper I consider one of the latest in the long line of attempts to develop a view of this kind, proposed by Alva Noë in Action in Perception. I will argue that Noë's attempt to account for being coloured in terms of looking coloured is no more successful than previous attempts. But its provides a platform from which to develop an alternative account of what it is to be coloured. Broadly speaking dispositional theories of colourof which Noë's account of colour is an example-respect the intimate connection between being coloured and looking coloured, but mischaracterise the sense in which objects 'look coloured'. I argue that 'look' should be understood objectively. This is not just to say to say that looks are genuine 'environmental properties': something with which dispositionalists can, and (as in Noë's case) do, agree. It is also to say, in contrast to the dispositionalist, that looks are properties that transcend specific circumstances of viewing. Objective looks are properties that objects have independent of the way they look in any particular conditions of perception, to any particular observer.

$\$ 1$ spells out some of the details of Noë's view, and situates it in relation to more traditional forms of dispositionalist theory. $\$ 2$ raises two problems common to theories of this general kind. These problems are then used to motivate the alternative objectivist account of colour that is developed in $\$ 3$. 


\section{Phenomenal Objectivism}

\subsection{Outline}

Noë's attempt to account for being coloured in terms of looking coloured starts with a reification of 'looks' or 'appears', such that when an object looks a certain way in a particular set of perceptual conditions, there is a relational property-a circumstance-relative look or appearance - that the object has in those circumstances. A white wall in shadow, for instance, has the circumstance-relative property of being grey-in-shadow; more generally, objects have the circumstance relative property of being F-in-c. Colours are then identified colours with 'patterns' of these circumstance-relative colours, or 'colour aspect profiles'.

Noë calls this position 'phenomenal objectivism'. Phenomenal objectivism is phenomenalist in the sense that colours are reductively identified with colour aspect profiles: they are nothing 'over and above' the patterns of looks that objects manifest in different perceptual circumstances, in particular there are no underlying 'real' colours that apparent colours are appearances of: colours contrast in this respect with observable properties like shape and size, because although objects have circumstance-relative shapes and sizes (corresponding to circumstance-relative colours)—such as being elliptical-from-here or being occluded-by-a-penny-on-a-plane-perpendicular-to-the-line-of-sight-from-bere (pp. 82-3) - they also have real shapes and sizes over and above their merely apparent properties. Phenomenal objectivism is objectivist, on the other hand, in so far as circumstance-relative looks are genuine mind-independent properties of the perceptual environment. The property that an object has of being grey-in-shadow is a relational property of that object, but because it is a relation between and an object and a light source-and crucially, it is not a relation between an object and a perceiving subject— the property is not in any sense mental, or more generally mind-dependent. ${ }^{1}$

\subsection{Phenomenal Objectivism and the Enactive Theory of Colour Perception}

As Noë presents it, phenomenal objectivism is an enactive theory of colour. Enactive theories of colour are called 'enactive' because they are supposed to march in step with the enactive theory of colour perception. According to Noë, to experience something as a particular colour is to experience it as having a particular colour aspect profile. Activity enters the picture because of the control that subjects enjoy over their experience of patterns of change in an object's colour appearance: as when you change the character of 
your experience by changing your position relative to the object, viewing the object under a different illumination, and so on. This ties the account of colour and colour experience to the overarching thesis of Action in Perception, that 'perceiving is a way of acting' (p. 1) that is constitutively dependent on implicit 'sensorimotor knowledge' of the effects of movement on sensory stimulation. On this view, to experience an object as having a certain colour aspect profile is to experience it as being such that its appearance would change given certain kinds of movements; or in other words, to experience it as having a specific 'sensorimotor profile'.

As it happens, it is debatable quite how naturally colour perception slots into the sensorimotor framework. Compared to the dependence on movement of our perception of shape, for instance, the dependence on movement of our colour experience is a comparatively poor relation. The strictly speaking movement-dependent sensorimotor contingencies associated with colour are restricted to a few minor kinds of manipulation, such as turning an object in relation to a light source, and some sub-personal, nonintentional, movements, like fixating on a coloured object so as to stimulate the foveal region of the eye which is densely populated with retinal cones. These sensorimotor contingencies are not at all like the rich range of movement-dependent sensorimotor contingencies afforded by shapes, properties that constantly change in appearance as we move in relation to them, or manipulate them in our hands. The range of object-dependent sensorimotor contingencies associated with colour-those ways in which an object's appearance changes depending upon its own movement throughout the environment and changes in that environment (pp. 64-65, 129-132) - are, of course, much more multifarious: an object's appearance not only changes with the illumination and background in different parts of the scene as it moves around, but it also varies if, remaining static, the ambient illumination or the colours of the surrounding objects change. Still, it is a moot point to what extent object-dependent sensorimotor contingencies are best described as involving knowledge of sensorimotor contingencies at all: these variations in the course of experience seem to depend as much on change in the environment as anything that we would naturally describe as movement.

The relation of phenomenal objectivism to the enactive theory of perception is not, however, my main focus in this paper. In whatever (possibly attenuated) sense phenomenal objectivism walks in step with an enactive theory of colour perception, the enactive theory of colour perception does not entail a phenomenalist theory of colour, any more than the enactive theory of shape perception entails a phenomenalist theory of 
shape. Colours could have rich sensorimotor profiles even if they were not identical to patterns of organization in how things look, just as shapes can have rich sensorimotor profiles without being reducible to the way that things change their apparent shape as your vantage point varies. Phenomenal objectivism and the enactive theory of perception are independent theories.

\subsection{Phenomenal Objectivism and Dispositionalism}

Of more immediate importance is the relationship between phenomenal objectivism and more traditional dispositional theories of colour. Anticipating the objection that phenomenal objectivism is merely dispositionalism by a different name (an objection commonly directed at the closely related views of colour that go under the banner of the 'ecological theory', as developed in, for instance, Thompson 1995), Noë is keen to distinguish phenomenal objectivism from dispositionalism. According to his official characterisation, dispositionalism is the view that 'to be red, for example, is to be such as to look red to normal perceivers in normal lighting conditions', where 'look red' on the right hand side of this definition is spelt out in terms of sensational properties of experience, or qualia (p. 142). Phenomenal objectivism is supposed to represent an advance on dispositional theories of colour because it does not analyse 'looking coloured' in terms of subjective properties of experience, but in terms of genuine properties of the perceptual environment, thereby avoiding well known problems attendant on postulating sensational properties of experience.

But to the extent that there is daylight between phenomenal objectivism and dispositionalism, it is only because Noë's construal of the dispositionalist position is overly narrow. ${ }^{2}$ Whilst it is certainly true that some dispositionalists analyse 'looking red' in terms of sensational properties of experience, this is not definitional of the dispositionalist position. For instance, a view very similar to phenomenal objectivism can be found, in amongst others, Ryle. The commitment to the existence of private sensational properties notwithstanding, Ryle thinks that there is much to admire in phenomenalism (1949, pp. 223-7). His account of the nature of colour, like Noë's, is in essence a phenomenalist theory of colour. Although Ryle thinks that colours (like all properties on his view) are dispositions, he insists that they are not dispositions to produce in us sensations. Rather, they are dispositions of objects to look a certain way, where what it is for an object to look a certain way is taken as a basic, not further analysable, publicly ascertainable fact: 
Secondary Quality adjectives are used and used only for the publicly ascertainable facts about common objects; for it is a publicly ascertainable fact about a field that it is green, i.e. that it would look so and so to anyone in a position to see it properly (1949: 209). ${ }^{3}$

Of course, the fact that Noë employs a particularly narrow understanding of dispositionalism is not of itself a criticism. But as I will argue, whatever differences there are between phenomenal objectivism and dispositionalism in Noë's restricted sense of the term, these differences do not bear on the fortunes of phenomenal objectivism. Although the postulation of qualia might be problematic, the fundamental problems with dispositional theories of colour are independent of problems with any particular way of spelling out what it is for something to look coloured in a particular set of circumstances. The more fundamental problems stem from the assumption that it is possible to account for what it is for something to be coloured in terms of what it is for something to look coloured in a specific perceptual situation, and this is a commitment of dispositional theories and phenomenal objectivism alike.

\section{Colour Perception: Phenomenology and Epistemology}

\subsection{Colour, Shape and Size}

According to Noë, colour, shape and size differ in respect of the relationship between the respective circumstance-relative looks and the relata on which these relational properties supervene.

Apparent shapes are determined by the real shape of an object plus the object's (real) spatial relations: specifically its orientation with respect to the different points of space that constitute different possible points of observation. In this case, the relata on which the relational appearance property supervenes are therefore both of a kind: they are both spatial properties. Likewise, the apparent size of an object is fixed by the real size of the object plus the-real size of the-distance of the object from the point of observation. Again, the relata that determine the relational property are both of a kind: they are both sizes.

But things are supposed to be different in the case of colour. Because there are no real colours that lie behind colour appearances, circumstance-relative apparent colours supervene on properties that differ fundamentally in kind. This is obvious in the case of 
coloured objects, but it is worth noting that the point applies to the perceptual conditions as well. On the face of it, it is the colour of the background that in cases of simultaneous contrast affects the appearance of the object in the foreground: it is the black of the background that makes the white appear greyer. Likewise, on the face of it, it is the colour of the illumination co-determines the apparent colour of the object. This is more obvious in cases where the illuminant is clearly chromatic: for instance, when we see a white wall illuminated by blue light, or search for our car under orange sodium street lighting. But the same applies to variations between so-called 'white lights', like the various phases of natural daylight, candlelight, and most commercial and domestic illuminants, which themselves differ in colour depending on whether they are 'warmer' (yellowish or reddish) or 'cooler' (bluish). If, however, there are no real colours of objects over and above the set of apparent colours, then presumably there are no real colours of the illumination or the background to co-determine the object's apparent colour, either. These appearances cannot be taken at face value: whatever properties of objects and perceptual conditions determine an object's apparent colour, they are not chromatic properties, but must be properties of some other kind.

I consider Noë's reasons for thinking that colours differ from shapes and sizes in being reductively identifiable with patterns of circumstance-relative looks properties in \$3. For the time being, however, I simply want to set this questions to one side, and consider the problems that the putative disanalogy raises. There are two main problems: one phenomenological, one epistemological.

\subsection{The Phenomenology of Colour Experience}

The phenomenological objection to phenomenal objectivism is the counterpart of a problem with more traditional forms of phenomenalism. In a discussion of phenomenalism, for instance, Ryle (1949: 223) remarks that even stating traditional phenomenalist positions is problematic. In particular, the seemingly natural claim that, for instance, 'there is nothing more to be said about the gate-post than how it does or would look, sound, feel, etc.' is at best misleading: if phenomenalism is correct, then by hypothesis there is no gate-post over and above the collection of gate-post appearances to which 'it' in this characterization can refer, as the gate-post just is the collection of gate-post appearances.

The problem is not just that it is difficult to state the phenomenalist position without exercising due caution: the problem that Ryle highlights appears to be 
symptomatic of an underlying malaise. The natural temptation to refer to gate-posts independent of the way in which gate-posts appear is symptomatic of the fact that our experiences extend beyond the appearances to which phenomenalist accounts of gateposts are restricted. Our experiences outstrip what is by hypothesis available to the phenomenalist, stretching beyond gate-post appearances to the gate-posts themselves: when we see a gate-post, we generally see it as a voluminous three-dimensional object with a back-side, even if its back-side is not visible from the spatial position we occupy; we perceive the gatepost as continuing behind the parts of the gate that occlude our view of it; we perceive to be something that extends beyond the specious present; and so on.

The tendency to go beyond the phenomenalist's appearances is an example of a ubiquitous phenomenon that Noë calls 'presence in absence'. As Noë stresses, presence in absence appears to be a primarily perceptual phenomenon. In particular, it does not seem to be something that we can simply explain away in terms of post-perceptual judgement. Considering amodally completed Kaniza figures (as illustrated in Figure 1), for instance, Noë remarks that:

We don't merely think the presence of the occluded bits: After all, they are, evidently, not present, but blocked from view (or rather, not drawn); it looks as if they are blocked from view. We experience the presence of the occluded bits even as we experience, plainly, their absence. They are present as absent (p. 61).

One experiences the presence of that which one perceives to be out of view (p. 63).

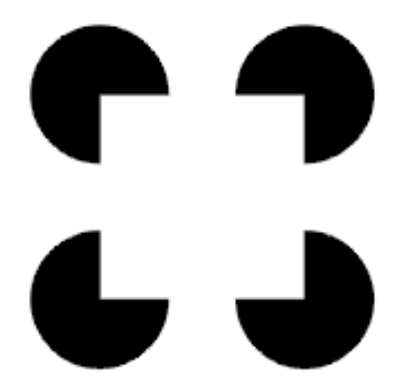

Figure 1: A Kaniza Figure.

Taking these descriptions of the phenomenology of presence in absence seriously, the natural inclination to go beyond the phenomenalist's appearances reflects the phenomenological inadequacy of phenomenalism. 
An analogous problem arises for phenomenalism about colour. The problem does not arise in exactly the same form: because phenomenal objectivism is not an entirely general theory, there are at least still objects and non-chromatic properties beyond the patterns of appearance; hence Noë's claim that ' $t$ the color of an object is a way its appearance varies as relevant conditions change' (p. 141) is not incoherent in the way that the incautious phenomenalist's description of the gate-post is, as there is at least an object over and above the appearances for the 'its' in this statement to refer to. The problem for phenomenal objectivism, however, is that the 'its' nevertheless appears to refer to the wrong kind of thing.

According to Noë, a special case of presence in absence is the phenomenon of perceptual constancy: the perceived constancy of a property throughout changes in the conditions under which it is perceived. Noë maintains that with respect to perceptual constancy, colour, shape and size are on a par. Just as he thinks that we perceive the roundness of a plate:

in the fact that it looks elliptical from here and that its elliptical appearance changes (or would change) in precise ways as your relation to the plate, or plate's relation to the environment, changes

so, he thinks that in exactly the same way:

we experience the color of the wall in the fact that the apparent color of the wall varies as lighting changes. We are able to experience the actual colour of the object as, so to speak, that condition which governs or regulates the way these changes unfold (pp. 127-8).

In passing, it is worth noting that the claim that we perceive an object's real shape 'in' (or as it is sometimes put, 'by virtue of') its elliptical appearance is not unproblematic. In particular, it threatens to place real shapes and sizes beyond a veil of appearances, albeit real environmental appearances, blocking our epistemic access to the underlying reality; phenomenalism, in contrast, at least has the advantage of tearing down the iron curtain between appearance and reality. But I do not want to pursue this worry here. The important point here is just the claim that we perceive the object's shape-which is to say its real shape-at all. The real shape is indispensable to the description of the phenomenology. Indeed, this is precisely what we should expect from the fact that Noë 
regards the phenomenon of perceptual constancy as an instance of presence in absence, as the appearance of some one thing as present despite being absent: to say that the object's real shape appears to be present in its absence is to say that object appears to be really round even when it merely appears otherwise.

The problem, of course, is that if colour really is on a par with shape with respect to constancy, then the same should be true of colour. That is to say, an object's colourwhich is to say its real colour-should also be something that we perceive in its absence. This is how Noë himself describes the phenomenology of colour constancy in the passage quoted above, clearly regarding the colour-or as he goes on to call it 'the actual colour'-of the wall as something over and above the mere colour appearances. It is the colour itself that appears to persist throughout changes in its appearance due to variations in the perceptual conditions. For Noë, the 'actual colour' is that 'condition' which we perceive to 'govern or regulate'-by which he presumably means something like ground or explain - the way in which our experience of the object varies as the colour-critical conditions vary. By hypothesis, however, there is no colour to perceive 'in' the object's coloured appearances, in the way that there is a shape to perceive 'in' the plate's elliptical appearance: according to phenomenal objectivism, colour is nothing over and above the collection of apparent colours. ${ }^{5}$

We can illustrate the problem by substituting a statement of Noë's phenomenal objectivism-colours are the ways that apparent colours vary as the conditions changefor '(actual) colour' in his description of the phenomenology of colour constancy quoted above. Breaking this description in half, the first sentence:

(1) we experience the color of the wall in the fact that the apparent color of the wall varies as lighting changes

reduces to the tautologous claim that:

$\left(1^{*}\right)$ we experience the way the apparent colour of the wall varies as lighting changes in the fact that the apparent color of the wall varies as lighting changes.

Similarly, the claim that: 
(2) We are able to experience the actual colour of the object as, so to speak, that condition which governs or regulates the way these changes unfold

becomes the equally unilluminating:

$\left(2^{*}\right)$ We are able to experience the way the apparent colour of the object varies as lighting changes as, so to speak, that condition which governs or regulates the way these changes unfold.

As descriptions of the phenomenology of constancy, $\left(1^{*}\right)$ and $\left(2^{*}\right)$ are non-starters. Cases of perceptual constancy are cases in which objects look in some way the same and in some way different across a variety of different conditions of observation. Identifying colours with colour aspect profiles explains the differences amongst colour experiences in different conditions, but it does nothing to explain the similarity: according to phenomenal objectivism, the pattern of appearances is all that there is. What we need in addition to the set of circumstance-relative apparent colours with which Noë identifies colours is an underlying unifying property that we perceive to remain constant. Phenomenologically speaking, the perceived constancy of colour throughout changes in the colour-critical conditions appears to be the perceived constancy of the colour itself.

This problem with phenomenal objectivism is, of course, an instance of a well known problem with dispositional theories of colour in general. A standard criticism of dispositional theories of colour is that colours do not look like dispositions to appear coloured. One way of understanding this objection is as pointing out that the dispositional account is inconsistent with the phenomenon of colour constancy. As Johnston puts it, for instance:

(steady) colors don't look like dispositions; to which the natural reply is "Just how would they have to look if they were like dispositions?"; to which the correct response is that they would have to look like colored highlights or better, like shifting, unsteady colors (1992: 141).

Whatever differences there might be between dispositionalism and phenomenal objectivism, they do not bear on the phenomenological adequacy of phenomenal objectivism. Like dispositional theories of colour, and phenomenalist theories more 
generally, phenomenal objectivism is phenomenologically inadequate: phenomenologically speaking, being coloured is prior to looking coloured.

\subsection{The Epistemology of Colour Experience}

The problems for phenomenal objectivism ramify when we turn to the epistemological role of colour experience. As Noë's description of the phenomenology of constancy brings out, the experience of colours as properties that lie beyond colour appearances has an important epistemic dimension: we experience colours as properties that 'govern or regulate' the way in which coloured objects appear as the colour-critical conditions change. This is important from the perspective of perception-based action. Our understanding of the ways in which an object's colour contributes to an its behaviour in counterfactual situations grounds the expectations that we are able to form about it: it is only by having expectations about how that object will behave across different contexts that we are able to work on, and with, that object. Needless to say, colours are not unique in this respect: the same is true of properties like shape and size.

The problem with phenomenal objectivism is that because colours are nothing more than patterns of organization in how things look, we can only know how an object's appearance will change across contexts by perceiving how its appearance actually changes as the perceptual conditions vary. We cannot account for this understanding in terms of perceiving the property that governs or regulates this behaviour, as there is no such property: there is no 'principle of unity' to the manifold appearances, nothing that can ground our expectations about how the course of our experiences will unfold. This means that we have no way of forming expectations about how an object's appearance will change as the viewing conditions vary, because we have no way of knowing, on the basis of a currently manifested appearance, which colour aspect profile this appearance is a member of: according to the phenomenal objectivist, that a given appearance is a member of a given colour aspect profile is at best a brute fact. Indeed, without any principle of unity underlying the different appearances, phenomenal objectivism lacks the resources to explain why it is that we group different circumstance-relative looks into distinct colour aspect profiles at all. Why is it that we group different appearances into distinct patterns, rather than taking them to be distinct, unrelated appearances. Or put the same point another way, how do we distinguish mere difference of apparent property from difference of the colour aspect profile that this property is a property of? (Cf. Schellenberg 2007) 
Noë's account of individual circumstance-relative looks acknowledges, but fails to answer these problems. Building on a proposal by Pettit (2003)—and consonant with the enactive approach to perception developed in Action in Perception-Noë's account of the circumstance-relative looks that constitute the building blocks of the colour aspect profiles with which phenomenal objectivism identifies colours is co-ordinate with an account of our experience of these properties. Circumstance-relative looks are identified with powers of objects to produce certain kinds of experience, where the experiences in question are identified with reference to certain kinds of behavioural capacity, rather than any intrinsic sensational properties. This account of what it is to experience something as looking red in a particular set of perceptual circumstances-for instance, to look red 'here and now'-has two parts: first, to experience something as looking red is to see it as looking such that we could discriminate it from other things in certain ('red appropriate') ways; second-and it is at this point that Noë's account touches the unity objection-to see something as looking red also requires a subject to experience it as such that 'it would look to vary in appearance in a range of comprehensible ways, given the color aspect profile of the relevant red' (p. 140).

As it happen, neither part of the proposal is unproblematic. The claim that in experiencing something as red we see it as being discriminable from other things, for instance, builds an incredible amount into the phenomenology of colour experience: some estimates put the number of discriminable colours (at the level of just noticeable differences under controlled conditions) at around 10 million; restricting ourselves to the colours that are discriminable under more normal conditions, the number probably still runs into the hundreds, if not the thousands; and even if we just consider relatively coarse grained colours-like scarlet, mauve, pink, or perhaps the still more coarsegrained colours red, green, blue - the phenomenology of colour experience will still turn out be incredibly complex: is it really phenomenologically plausible to suppose that when something looks red it also looks not green, blue, yellow, black, white, orange, purple, pink, brown, grey, cyan, chartreuse...? $?^{7}$ Indeed, ascribing this content to experience is not merely implausible; it is potentially incoherent. Noë's account of what it is for something to look red here and now in terms of how it differs in look from other things is viciously circular. In order to understand what it is for something to look red we need to understand how something that looks red is different from something that looks green, looks yellow etc.. What it is for something to look red is therefore defined in terms of a whole range of further looks. But the account of what these further looks are themselves 
depends upon an account of what, in the first place, it is for something to look red. Reapplying the general account of 'looks $F$ here and now' to looks green, for instance, part of what it is for something to look green is that it looks such that it would look discriminable in colour from something that looks red. But this makes the content ascribed to the original experience of something that looks red incoherent: what it is for something to look red is such that it looks discriminable from something that looks green, which is itself for something to look discriminable from something that looks red. But what it is for something to look red is what we were trying to give an account of in the first place.

This circularity because still more pressing when we consider the second condition that Noë places on the account of what it is for something to look red here and now. To say that something looks red in a specific set of circumstances involves certain counterfactual commitments. Part of what it is for something to look red here and now is for it to be such that it would vary in appearance in certain ways given certain changes in the perceptual conditions: looking red here and now is part of a unique colour aspect profile; as Noë puts it, we understand that an object that looks red here and now will vary in appearance as the colour conditions change 'in the "red appropriate" ways' (p. 139). But how do we group appearances together into different profiles in this way? Why suppose that this look in these conditions is part of precisely this colour aspect profile? After all, it would not be appropriate to group the same look in different conditions as part of this colour aspect profile, as objects look differently in different conditions: if the object appeared this way in different conditions, then its appearance would be part of a different colour aspect profile. Conversely, it would not be appropriate to group a different look in the same conditions as part of this colour aspect profile. But what explains our understanding of this? The natural answer is that we only group this appearance in these conditions with the other members of the red colour aspect profile because we already know that this is the way that red things appear in these conditions: we know that this appearance is appropriate to red things in these conditions. But this involves exploits a prior understanding of what it is for something to be red: to be red is to look red in precisely these conditions; being red is what makes it true that in these conditions a thing would look precisely like this.

This type of problem is, of course, familiar from discussions of phenomenalism and dispositionalism. Without a principle of unity to which we have epistemological access, phenomenalism, for instance, offers no way of explaining how we group 
appearances together into different objects (cf. Strawson 1966). Why suppose, for instance, that something that appears a certain way in these conditions would appear some other way in another set of conditions? What grounds do we have for grouping distinct appearances in this way? According to the phenomenalist, the grouping of appearances into distinct objects is simply a brute fact. But how then can we know how the object would behave in various counter-factual circumstances: we only seem to be able to know how the object would appear under different circumstances by seeing how it does in fact behave in these circumstances.

An analogous problem arises for traditional dispositional theories of colour as well (cf. Kalderon ms). Objects that have a disposition to appear a particular way in a certain set of circumstances are disposed to appear otherwise as the conditions vary; indeed, perceptual relativity of this kind is one of the main motivations for the dispositionalist position in the first place, just as it is for Noë's phenomenal objectivism. But again the question is how we can be in a position to know how the object will appear as the conditions vary if there is no property to which we have epistemological access that unites the different appearances. In advance of actually seeing how the object behaves as the conditions vary, we have no reason for thinking that an object that looks a certain way in these conditions will look one way rather than another in another set of conditions.

In effect, this is an instance of familiar worries with dispositional theories of colour about circularity. The dispositionalist tries to account for being red in terms of looking red. But if understanding the analysandum 'looks red' involves a prior understanding of the constituent term 'red', then we can only understand the analysandum if we already understand the analysans. Treating 'looks red' as a straight-forward function of its components in this way makes broadly speaking dispositionalist theories of colour viciously circular: there can be no hope of accounting for what it is to be red in terms of what it is to look red if understanding looking red itself presupposes an understanding of being red. As Sellars remarks: "the minute one gives "red" (on the right-hand side) an independent status, it becomes what it obviously is, namely "red" as a predicate of physical objects, and the supposed definition becomes an obvious circle', (1956, p. 36;). In other words, being coloured is also prior to looking coloured epistemologically speaking. 


\section{Looking Coloured, ObJectively SPEAKING}

\subsection{Colour and Shape: An Asymmetry?}

I have argued so far that being coloured is prior to looking coloured. This invites an obvious question: what, in the first place, is it for something to be coloured? Exactly is it that looking coloured is parasitic on?

This question is particularly pressing in light of an argument that Noë presents for thinking that there could be nothing in the case of colour that corresponds to real shape. According to Noë, the view that there are real colours, analogous to real shapes, is incoherent:

colours, unlike shapes, it would seem, are themselves looks. This would seem to make apparent colours the looks of looks, a notion that is probably not coherent. The problem, at base, is this: If colours, in contrast with shapes, are ways things look, then it is not possible to explain our experience of the actual colour of a thing in terms of looks, in the way that we were able to explain the experience of the actual shape of a thing in terms of our experience of how it looks (its P-shape) from here. For the way a thing looks with respect to color from here is just another experience of color (p. 133).

Consistent with the phenomenology of perceptual constancy, we cannot try to avoid the putative incoherence of predicating looks of looks by denying that colourswhich is to say, real colours-are themselves looks. Insofar as colours are those properties that we perceive to remain constant throughout variations in the object's appearance across different perceptual conditions, colours are at least properties that look a certain way. This therefore just leaves two options: deny that there are looks of colours or deny that there is any incoherence in predicating looks of looks. In \$3.3 I will argue for the latter option; first, however, I want to say something in support of the view that colours have looks.

\subsection{Do Colours have Looks?}

The first kind of response to the putative incoherence is to accept the claim that colours are looks, but deny the claim that there are any further looks of these looks. This would be to deny that there are any apparent colours in Noë's sense, and effectively adopt an adverbialist theory of colour appearances. From the adverbialist perspective, phenomenal objectivism involves an illegitimate reification of 'looks' at the very outset. From the 
platitudinous claim that 'coloured things look or appear different as the circumstances vary', the phenomenal objectivist infers that 'for each circumstance, there is a look, or an appearance, that the coloured thing has'. But it is by no means obvious that the inference from ' $\mathrm{x}$ appears F' to 'there is an F-appearance that $\mathrm{x}$ has' is valid. By comparison, sensedatum theorists aside, few would accept the corresponding inference (removing your glasses) from 'this looks blurry' to 'there is something that has a blurry look'; in this case, it seems more natural to suppose that 'looks' functions as an verb and 'blurry' is merely an adverb that modifies the manner or way of looking (cf. Siewart 2006).

Whilst this approach avoids any incoherence there might be in predicating looks of looks, however, it is not unproblematic. Generally speaking, it is not sufficient to show that the inference from appears to appearances is always illegitimate to point out that there are particular cases in which the inference fails, as the illegitimacy of the inference might simply depend on special features of the particular case. There are certainly a whole range of cases in which we are happy to use 'look' or 'appearance' as a substantive: when we talk about the look of a painting, an unkempt appearance, or when style magazines entreat us to 'get the look' of our favourite celebrities. As O'Shaughnessy, with characteristic eloquence, remarks:

it is certain that appearances matter vastly to us. Think of 'the face that launched a thousand ships'. Here we are talking of the peculiar efficacy in human life of a mere visual appearance. It was the look of Helen's face, rather than its chemical or electrical or pheronomic properties, that caused such a furore (2000: 570).

Indeed, not only is it natural to talk of looks as properties of objects-rather than describing the manner in which these objects appear to us-but it is no less natural to talk about the look or appearance of colours themselves. Although that which appears is often an object- the wall appears to be lighter over there, dirty over here, and so onproperties can themselves occupy the place of the grammatical object: colours can appear vibrant, washed out, darker in shadow, lighter than others, and so on.

The point does not merely depend on facts about the way in which we use the 'looks' locution. The naturalness of using 'apparent colour' as a substantive is underwritten by the fact that we can attend to, and by so doing identify, apparent colours. In the normal course of events, we don't notice merely apparent colours: if you glance at the wall, it will look to you to be homogenously coloured and you won't notice the differences in apparent colour where different parts of the wall are in shadow. The 
same goes for apparent shapes and sizes: we ordinarily don't notice the size or shape of the region of the plane perpendicular to the line of sight required to perfectly occlude an object, but attend only to the real shape or size of the object. But to say that we don't typically notice appearance properties isn't to say that we can't perceive them. We can attend to apparent colours, shapes and sizes by screening off the surrounding context, and adopting the painter's perspective (cf. Noë pp. 82-3, 165-7).

Once we admit in general the legitimacy of reifying 'looks', the problem with denying that there can be looks of looks is that we are committed to an unmotivated asymmetry between looks of objects and looks of those looks. It would need to explained in what way the legitimate inference from 'material objects look coloured' to 'there is an look that material objects have' is supposed to differ from the illegitimate inference 'coloured things look different as the circumstances vary' therefore 'for each circumstance, there is a look that the coloured thing has'. Both involve a reification of looks. If there is a problem with the reification of 'looks' in the second case, it cannot be because it is a reification of looks per se. There would have to be something special about the case that makes this reification illegitimate. But what could this be?

\subsection{Subjective and Objective Looks}

Pending further motivation for an adverbialist treatment of looks of looks_-and also in part to undermine one source of motivation for this view-I want instead to suggest a different response to Noë's argument: the predication of looks to looks is not incoherent at all. In particular, I want to suggest that the claim that predicating looks of looks is incoherent depends on a failure to bear in mind a distinction, that elsewhere Noë himself draws attention to, between different senses of 'looks'.

Iterative looks statements are not obviously incoherent. Teenagers invariably have a look that to their parents looks ridiculous: here, looking ridiculous is being predicated of a property of the teenager, namely the teenager's look. Similarly, a painting might have the look of a Rembrandt, but not look like a Rembrandt (which is to say, have the look distinctive of paintings that have the look of a Rembrandt) to me, if I am an artistically naïve observer or if the conditions of observation are not ideal: here, looking unlike a Rembrandt is predicated of something that has the look of a Rembrandt. There does not appear to be any obvious incoherence in either of these predications of looks of looks.

Of course, says that iterative looks are not in general incoherent is consistent with the existence of a special problem in the case of colour. As Noë sees it, for instance, the 
problem with predicating perspectival looks of a real colour is ultimately that 'the way a thing looks with respect to color from here [i.e. its perspectival look] is just another experience of color'. The thought seems to be that an apparent colour cannot stand to a real colour, in the way that apparent shape stands to real shape, because the apparent colour and the real colour both need to be understood in terms of our experience of the object. ${ }^{10}$ That is, we cannot understand what it would be for an object to look one way in respect of colour in a particular set of perceptual circumstances whilst looking a different way in respect of colour more generally, because we cannot simultaneously experience the object as appearing two different ways with respect to colour. The circumstances in which an object is seen determines the way the object looks in respect of colour, and 'screens off' its looking any other way: so, for instance, we cannot experience part of a wall that is in shadow as simultaneously looking grey and white, as the first look-the look in these particular circumstances, namely grey—screens off the second look-the object's more general look, namely white.

But why limit the properties that we are able to perceive in this way? By contrast, we do not think that there is any problem in simultaneously perceiving a wall to be cracked, dirty, too high to climb, to the left of the door, and so on.

Presumably the specific problem with colour-related properties arises because the two looks that we want to attribute to the object are incompatible: the wall in shadow cannot simultaneously look grey and white because nothing can be both white and grey. But this argument equivocates on 'looks'. We can distinguish two senses of 'looks', corresponding to two different properties of objects. In the perspectival, circumstance-relative, or what we might also call the subjective sense, looks are essentially tied to the experiences of particular subjects in particular circumstances of perception. To say that these looks are perspectival or subjective need not be to deny that they are 'environmental properties': that is, that they are relations between objects and conditions of perception, and not perceiving subjects. The point rather is that subjective looks can only be perceived in very specific circumstances of perception: this is a very fine-grained sense of looks, fine-grained enough to generate a different property for every different way an object can look. By contrast, in the non-perspectival or objective sense, looks are not essentially tied to the experiences of particular subjects in particular circumstances of perception: in the non-perspectival sense, an object's look transcends encounters with specific kinds of subjects in specific conditions of observation. Objective looks are 
properties that can be perceived across variations in the perceptual conditions, and are as such, are less coarse-grained than perspectival looks. ${ }^{11}$

Objective and subjective looks are not mutually incompatible. An object can simultaneously look objectively $F$ and look subjectively not-F (or at any rate, look G, where $G$ is inconsistent with F). A painting that has the objective look of a Rembrandt might have the subjective look of a Vermeer, if either the perceiving subject is not suitably receptive or if the conditions of perception are not appropriate; for instance, if either the subject is not suitably versed in art history or the painting badly hung. Likewise, the part of the wall that is in shadow might look subjectively grey given the conditions in which it is seen (i.e. in shadow), yet still look objectively white. If what we have here are two different kinds of property, then there is no reason why one should screen the other off: properties of different kinds are not mutually incompatible.

We can get a better sense of what the distinction between the two kinds of looks property consists in by considering the question of what constitute normal conditions for the perception of colour. Dispositional theories of colour that explain what it is for something to be coloured in terms of what it is for something to look coloured in normal conditions presuppose a non-trivial way of picking out the privileged set of conditions in terms of which colour is to be explain. A major problem with this is that, at least on the face of it, there is no one unique set of conditions that count as normal. As Sellars remarks, for instance, which conditions are normal for a given kind of perception is pretheoretically specified by 'a list of conditions which exhibit the vagueness and open texture characteristic of ordinary discourse’ (1956: \$18, p. 44).

At least one of the things that it means to point to the open texture of 'normal conditions' is that that there are a whole range of conditions in which, all else being equal, we perceive an object to be the colour that it really is: it generally does not make a difference to our ability to veridically determine an object's colour by sight whether we perceive it under natural daylight or an artificial illuminant that approximates to natural daylight; which of the many myriad different phases of natural daylight we perceive it under (like direct midday sunlight or the skylight of an overcast afternoon); whether the object is directly or indirectly illuminated; against which colour background it is seen; and so on. Our experience of the object's colour is robust across these different viewing conditions: perceiving the object in any of these conditions provides a good, albeit defeasible, warrant for judging that the object really is the colour that it is perceived to be. 
The problem with the way in which dispositionalists standardly invoke normal conditions in their analysis of being coloured is that across the broad class of conditions that count as 'normal' there is just the kind of variation in the character of colour experience to which dispositionalist often appeal to motivate their dispositional analysis in the first place. Although we can veridically perceive the colours of objects across many different conditions of perception, there is nevertheless substantial diverge in their appearance in exactly this set of conditions: just think again about the partially shaded wall. ${ }^{12}$ If we are operating with a sufficiently fine-grained sense of looks to motivate the claim that an object's appearance changes as the perceptual conditions change, then objects look different depending on variations in conditions which, given the open texture of ordinary discourse, count as normal. It is only if we operate with a more coarse-grained sense of looks that we are able to accommodate the fact that objects look the same in these different conditions.

Needless to say, the distinction between subjective and objective looks properties has application beyond the case of colour, perhaps most obviously in the case of shape and size: just as an object's objective colour is a property that we perceive in all roughly speaking normal circumstances, the object's objective shape (for instance) is a property that we perceive across conditions of viewing that are normal for shape perception. Indeed, the comparison to shape in turn helps further elucidate the notion of an objective look.

To say that colours are objective looks does not entail that colours are nothing more than objective looks, any more than saying that shapes are objective looks entails that being shaped is nothing more than being such as to look shaped across a wide range of more or less normal conditions. Shapes have a functional role that extends beyond their being such as to look a certain way to suitably placed perceivers: they effect the way in which their bearers interact with other material objects, determining amongst other things whether they roll down shallow inclines or fit through holes cut in rigid materials. Similarly, it is consistent with the claim that colours are objective looks that the functional role of colour is not exhausted by their effects on perceiving subjects: so, for instance, colours can affect the colours of other material objects, as in cases of simultaneous contrast or (at least in a rough-and-ready sense) physical colour mixing (Broackes 1992: 194-202); indeed, it is consistent with the claim that colours are objective looks that colours are identical with surface reflectance properties of material objects, as physicalists about colour suggest. The important point is just that colours are at least 
objective looks. The phenomenology of colour constancy commits us to the view that colours are non-perspectivally perceivable properties. Whether there is more to say about them is an open question.

\section{CONCLUSION}

Noë's phenomenal objectivism is the latest attempt to account for being coloured in terms of looking coloured, in the perspectival sense of the term 'look'. Phenomenal objectivism is no more successful than previous attempts to achieve this explanatory feat; it falls prey to the same basic objections as more traditional dispositional theories of colour, and indeed, structurally similar objections to phenomenalist theories of the external world in general.

The alternative view, that to be coloured is to look coloured, objectively speaking, in contrast, avoids the problems with phenomenal objectivism. Consistent with the phenomenology of perceptual constancy, colours are properties which are perceived to remain constant through out variations in the perceptual conditions; and it is this perceived commonality that explains the epistemological significance of colour perception: it is by perceiving the properties that 'govern or regulate' the way in which an object's appearance changes as the conditions change that makes possible perceptuallybased action. In this respect, the view that colours are objective looks is consistent with the claim that being coloured is prior to looking coloured. At the same time, however, this view is able to acknowledge that was at least something right with the dispositional analysis all along. Where the dispositionalist falls down is in taking subjective or perspectival looks as basic, and formulating an account of being coloured in these terms. But the grain of truth in broadly speaking dispositional theories of colour is that there is nevertheless an intimate connection between being coloured and looking coloured: what it is for something to be coloured is for it to look coloured in the objective sense of term. ${ }^{14}$

\section{REFERENCES}

Block, N. 2001. Behaviorism revisited. Commentary on O'Regan and Noë Behavioral and Brain Sciences, 24: 977-978.

Broackes, J. 1992. The Autonomy of Colour. Reprinted in A. Byrne and D. Hilbert (eds.) Readings on Color. Cambridge, Mass.: MIT Press.

Evans, G. 1980. Things Without the Mind. Reprinted in Collected Papers. Oxford: 
Clarendon Press, 1985.

Johnston, M. 1992. How to Speak of the Colors. Reprinted in A. Byrne and D. Hilbert (eds.) Readings on Color. Cambridge, Mass.: MIT Press.

Kalderon, M. ms. Metamerism, Constancy, and Knowing Which.

Martin, M.G.F. 2007. The Problem of Other Minds, Royal Institute of Philosophy Lecture Series, 2006-7.

Noë, A. 2004. Action in Perception. Cambridge, Mass.: MIT Press.

O'Shaughnessy, B. 2003. Consciousness and the World. Oxford: Oxford University Press.

Peacocke, C. 1983. Sense and Content. Oxford: Clarendon Press.

Pettit, P. 2003. Looks as Powers. Philosophical Issues 13: 221-52.

Ryle, G. 1949. The Concept of Mind. Penguin Books: Harmondsworth.

Schellenberg, S. 2007. Action and Self-Location in Perception, Mind 116.

Sellars, W. 1956. Empiricism and the Philosophy of Mind. Harvard: Harvard University Press, 1997.

Siewart, C. 2006. Is the Appearance of Shape Protean. Psyche, 12.

Strawson, P.F. 1966. The Bound of Sense. London: Methuen.

- 1979. Perception and its Objects. In G.F. MacDonald (ed.) Perception and Identity (London: Macmillan).

Thompson, E. 1995. Colour Vision. London: Routledge. 
${ }^{1}$ Noë makes this point by saying that relational properties are not 'subjective'. The term 'subjective', and its contrary 'objective', are notoriously slippy. I avoid using the term 'subjective' here because there is at least one sense in which these kinds of looks properties are naturally thought of as subjective, and this is that they are tied to specific conditions of observation. But nothing turns on the terminological decision.

${ }^{2}$ Or worse, phenomenal objectivism is distinguished from dispositionalism simply by misrepresenting the dispositionalist position. Noë sometimes appears to equate dispositionalism with eliminativism; for instance, when he contrasts phenomenal objectivism with the views of dispositionalists ('and others') who 'deny that colour is real is because they hold that colour is subjective (e.g., a kind of sensation). Colour, according to these theories, is in us, not in the world (p. 150). Whatever else the dispositionalist position amounts to, to say that colours are dispositions of objects to look coloured is at least to deny that colour is 'in $u s$, not in the world.

3 Compare Evans 1980. It is clear that Evans, like Ryle, thinks that there is something right with phenomenalism, at least as far as colours are concerned. In particular, he agrees with phenomenalist view, ultimately deriving from Berkeley, that the content of our secondary quality concepts can be distilled without remainder from what is given in pure sensory experience. Evans disagrees with the phenomenalist, and Ryle, however, in requiring that dispositional properties to look coloured be grounded in categorical properties of the object.

5 The passage from pp. 127-8 cited in the text is not an isolated occurrence. A few pages later, Noë claims that ' $[\mathrm{t}$ ] be a particular red is to bring about these sorts of apparent changes in how things look' (p. 143), apparently suggesting that there is a quality redness over and above the ways that red things appear that 'brings about' the changes in appearance. This is consistent with his description of the phenomenology of constancy in the paragraph immediately prior to that cited above. According to Noë, we see the uniformity of an homogenously coloured object 'behind or beneath (as it were), the variable appearance'; '...changes or nonuniformities in illumination do affect the apparent color of the object...but they do not affect our experience of the actual color... We experience color as that which is, in a wide range of cases, invariant amid that apparent color' (p.127). Compare the claim that we experience the wall as 'uniform in colour and as differently coloured across its surface' (p. 133, p. 164).

${ }^{7}$ This problem is exacerbated by the fact that Noë requires that the discriminatory capacities in question should not be too coarse-grained: to see something as looking red, for instance, is not just to experience it as looking such as to enable you to distinguish it from green looking things; it is also to be able to see it as 'lighter than this, darker than that, as more like this in respect of hue than that, although more like that in respect of brightness than this' (p. 139). Noë makes this requirement to avoid the charge that his account of the experience of looking red, and thereby looking red itself, is essentially behaviouristic: the objection, he thinks, rests on 'an overly simplistic account of the discriminatory capacities in question' (p. 139). But this seems to miss the point of the objection. The complexity (or 'maturity') of a subject's range of discriminatory capacities is irrelevant to the question of whether this account of their experience of something that looks red is behaviouristic. An account doesn't stop being behaviouristic simply because you throw in more behavioural dispositions to the mix. More of the same won't help. The problem is one of kind, not of degree. The problem with behaviourism is not that behaviourists try to account for experience 
in overly simplistic behavioural terms; it is that they try to account for experience in behavioural terms at all. Behaviourists attempt to account for experience in terms of what subjects can do, but this just gets things impossibly the wrong way around. Experience of colour does not consist in being able to discriminate colours from all other things. Rather, it is the necessary condition on which this ability depends. In effect, this objection is an instance of the general objection that enactive theories of perception are really nothing more than the behaviourist's new clothes (e.g. Block 2001). In general, the link that enactive theories of perception forge between action and perception is simply too tight. Perceiving is not a way of acting. Perception is what makes action possible.

${ }^{9}$ Noë himself uses this example, originally from Hacker, noting that 'looking like a Rembrandt to one may not be very strong evidence that the picture actually looks like a Rembrandt' (p. 80; see also 149-150).

${ }^{10}$ I presume that Noë cannot actually mean to make the identity statement that he appears to here: that the object's perspectival look is an experience of colour. This would make the perspectival look a property of the subject, not a property of the object. The claim that we can only understand the property in terms of experience of it is intended to avoid this problem.

11 The distinction between these different senses of 'looks' draws on the discussion of 'objective looks' in M.G.F. Martin 2007. Compare Peacocke's notion of an observational concept, which is the concept of a property like squareness, such that 'It is not epistemically possible for someone who has the concept of squareness that: from all the different angles from which an object may be seen, it is seen as square, his perceptual mechanisms are operating properly, the circumstances of perception (the environment in which the causal processes take place) are normal, the object is constant in shape, and yet that presented object not be square' (1983: 99). The distinction is perhaps related to one that Noë himself draws (p. 84) in the case of shape between looks, like the property of being elliptical-from-here, and 'visible qualities', like being circular (simpliciter). Neither Peacocke nor Noë offer analogous accounts of colour, however.

12 That the way an object looks can vary in normal conditions is something Noë himself notes (p. 142), although he thinks that this means we need to identify colours with sets of apparent colour rather than particular apparent colours in specific situations.

14 Acknowledgements. 